\title{
Analisis Sistem Penjadwalan Produksi Berdasarkan Pesanan Pelanggan dengan Metode FCFS, LPT, SPT dan EDD Pada PD. X
}

\author{
Rosi Indah Safitri \\ Program Studi Teknik Industri, Universitas Indraprasta PGRI, Jakarta \\ Indahrossi22@gmail.com
}

\begin{abstract}
Abstrak - PD X merupakan perusahaan industri yang bergerak dibidang pangan yaitu saus. Tujuan penelitian adalah untuk mengetahui metode pengurutan pekerjaan terbaik yang dapat mengoptimalkan proses produksi agar meminimalkan waktu penyelesaiannya. Metode yang digunakan peneliti dalam melakukan penelitian iniadalah metode job sequencingyang terdiri dari first Come First Sarve (FCFS),Earlist Due Date (EDD), Shortest Processing Time (SPT), dan Long Processing Time (LPT). Data yang digunakan dalam penelitian adalah wawancara, dokumentasi dan studi pustaka yang diperoleh dari perusahaan.Penelitian ini membandingkan hasil perhitungan rata-rata waktu penyelesaian pesanan, total waktu keterlambatan, dan nilaiutilitas dari keempat metode tersebut.Hasil dari penelitian ini ternyata metode EDDdan SPT merupakan metode yang paling optimal dengan nilai total waktu penyelesaian 189 hari, total keterlambatan 13 hari, dan mempunyaiutilitas $15 \%$ di bulan Juli. Sedangkannilai rata-rata waktu penyelesaian selama 172 hari, total keterlambatan 12 hari, dan mempunyai utilitas 17\% di bulan Agustus. Upaya yang dapat dilakukan oleh PD X untuk membuat penjadwalan produksi yang optimal dapat menggunakan metode EDDatau SPT karena selain terbukti mempunyai nilai yang paling baik dari metode yang lain, metode ini juga sangat sesuai dengan keadaan PD X yang menerapkan sistem produksi make to order, dimana penyesuain pesanan pelanggan sesuai dengan lead time yang ada.
\end{abstract}

Kata kunci- Penjadwalan Produksi, FCFS, EDD, SPT, dan LPT.

\begin{abstract}
PD X is an industrial company engaged in food, namely sauce. The purpose of the research is to find out the best work order method that can optimize the production process in order to minimize the completion time. The method used by researchers in conducting this research is the job sequencing method consisting of first Come First Sarve (FCFS), Earlist Due Date (EDD), Shortest Processing Time (SPT), and Long Processing Time (LPT). The data used in the study are interviews, documentation and literature study obtained from the company. This study compares the results of the calculation of average order completion time, total time delay, and utility value of the four methods. The results of this study turned out that the EDD and SPT methods were the most optimal with an average score of 189 days, a total delay of 12 days, and a utility of $15 \%$ in July. While the average completion time is 172 days, the total delay is 12 days, and the utility is $17 \%$ in August. Efforts that can be made by PD X to make optimal production scheduling can use the EDD or SPT method because besides being proven to have the best value from other methods, this method is also very suitable with the condition of PD $X$ which implements the production system make to order, where Customizing customer orders according to the lead time.
\end{abstract}

Keywords-Production Scheduling, FCFS, EDD, SPT, and LPT

\section{Pendahuluan}

Organisasi industri merupakan salah satu mata rantai dari system perekonomian, karena memproduksi dan mendistribusikan produk [1]. Sistem produksi terdiridari kumpulan sub sistem yang saling berinteraksi dengan tujuan mentransformasi input produksi menjadi output produksi. Input produksi ini dapat berupa bahan baku, mesin, tenaga kerja, modal, dan informasi. Sedangkan output produksi merupakan produk yang dihasilkan, berikut hasil sampingannya seperti limbah, informasi, dan sebagainya [2]. Penjadwalan yang baik akan memaksimumkan efektifitas pemanfaatan sumber daya yang ada, sehingga penjadwalan merupakan kegiatan yang penting dalam perencanaan dan pengendalian produksi. Penjadwalan adalah pengurutan dan pembuatan produk secara menyeluruh yang di kerjakan pada beberapa buah mesin [3].

Dalam sebuah sistem penjadwalan produksi menggunakan banyak sekali metode.Penelitian-penelitian tentang sistem penjadwalan dengan berbagai macam metode penjadwalan telah banyak dilakukan. Penerapan metode asas prioritas pada proses pembubutan dalam produksinya. Penelitian dilakukan di koperasi batur jaya. Tujuan dalam penelitian tersebut adalah untuk merekomedasikan beberapa alternatif untuk membantu penjadwalan proses pembubutan dengan memprioritaskan pesanan yang terlebih dahulu diproses [4].

PD $\mathrm{X}$ merupakan perusahaan yang bergerak dibidang pangan yaitu saus.Perusahaan tersebut memproduksi berbagai macam merk saus dengan kemasan dus dan krat.Perusahaan ini menggunakan sistem make to order dengan mendahulukan pemesanan yang pertama kali masuk. Untuk industri yang menganut sistem make to order itu fokus terhadap pelanggan untuk melakukan proses produksinya. Maka dari itu, dalam sistem penjadwalan produksinya perusahanan menggunakan metode FCFS dimana pesanan pelanggan yang pertama kali masuk itu yang akan diproses terlebih dahulu. Namun banyaknya permintaan yang masuk dengan keterbatasan kapasitas produksi dan sumber dayanya membuat perusahaan mengalami keterlambatan dalam produksinya yang mengakibatkan keterlambatan juga pada pengiriman ke konsumen. 
Banyaknya sistem penjadwalan yang ada membuat perusahaan harus selektif memilih metode penjadwalan mana yang kan diterapkan dalam industrinya. Dengan begitu perusahaan berupaya untuk memiliki penjadwalan yang efektif dan efisien sehingga dapat meningkatkan produktivitas serta mengoptimalkan seluruh sumber daya agar dapat menghasilkan produk yang berkualitas dan memenuhi standar serta memenuhi semua keinginan konsumen.

Prioritas job merupakan prioritas kerja tentang job-job mana yang diseleksi dan diprioritaskan untuk diproses [5]. Yang bertujuan untuk membuat prioritas urutan pengerjaan dalam pemprosesan order-order yang masuk.Aturan prioritas terdiri dari metode SPT, EDD, dan LPT yang mencoba untuk meminimalkan waktu penyelesaian, jumlah pekerjaan dalam sistem, keterlambatan pekerjaan dan memaksimalkan utilisasi[6].Dengan begitu perusahaan dapat mengurangi keterlambatan dalam produksinya dengan meningkatkan penggunaan sumber daya yang ada sehingga total waktu proses berkurang dan produktivitas pun meningkat.

\section{Metode Penelitian}

Dalam penelitian ini penulis menggunakan metode job sequencingatau pengurutan pekerjaan yang merupakan penentuan urutan pekerjaan yang harus di lakukan pada setiap pusat kerja [7]. Dalam job sequencing terdapat 4 metode yang digunakan yaitu :

1. FCFS (first come first served), merupakan pekerjaan yang pertama datang akan diproses terlebih dahulu.

2. SPT (short processing time), merupakan pekerjaan yang memiliki waktu penyelesaian lebih pendek akan diproses terlebih dahulu.

3. LPT (long processing time), merupakan pekerjaan yang memiliki waktu penyelesaian lebih panjang akan diproses terlebih dahulu.

4. EDD (earlist due date), merupakan pekerjaan dengan batas waktu paling awal akan diproses terlebih dahulu.

Dimana perhitungan dari keempat metode tersebut adalah sebagai berikut :

1. Waktu penyelesaian rata-ra
2. Utilisasi $=\frac{\sum P T}{\sum C T} \times 100$

3. Keterlambatan rata-rata $=\frac{\sum L P}{\text { Jumlah orderan }}$

Dimana :

$$
\begin{aligned}
& \sum \mathrm{CT}=\text { Total Waktu Penyelesaian } \\
& \sum \mathrm{PT}=\text { Total Waktu Proses } \\
& \sum \mathrm{LP}=\text { Total Keterlambatan }
\end{aligned}
$$

Setelah mengolah dan memperhitungkan dari keempat metode tersebut langkah selanjutnya adalah membandingkan semua hasil dari keempat metode tersebut dengan perhitungan menggunakan software POM for windows5.0. QM adalah kepanjangan dari quantitatif method yang merupakan perangkat lunak dan menyertai buku-buku teks seputar manajemen operasi [8]. QM for windows merupakan gabungan dari program terdahulu DS dan POM for windows, jadi jika dibandingkan dengan program POM for windows modul-modul yang tersedia pada QM for windows lebih banyak. Namun ada modul-modul yang hanya tersedia pada program POM for windows, atau hanya tersedia diprogram DS for windows dan tidak tersedia di QM for windows [9]. Hasil yang dibandingkan yaitu rata-rata waktu penyelesaian pesanan, total waktu keterlambatan, dan nilai dari utilitas.Dengan hasil yag diperoleh tersebut akan menentukan metode terbaik manakah yang akan bisa digunakan oleh PD $\mathrm{X}$ untuk meningkatkan produktivitas serta mengoptimalkan seluruh sumber daya agar dapat menghasilkan produk yang berkualitas dan memenuhi standar, serta dapat memenuhi semua keinginan konsumen secara tepat waktu.

\section{HASIL DAN PEMBAHASAN}

Setiap harinya PD X memproduksi berbagai macam merk saus diantaranya yaitu saus sambal sedap (SS), saus 58 (S58), dan saus Surabraja (SB). Dari ketiga merk saus tersebut akan dikemas dalam varian dus dan krat/botol. Fasilitas produksi yang dominan di dalam pabrik adalah mesin dan peralatan. Tanpa adanya benda tersebut produksi tidak akan bisa berjalan [10]. Perusahaan menggunakan 9 macam mesin dalam proses produksinya. Dimana mesin-mesin tersebut memiliki kapasitas nya masing-masing.Untuk memproduksi semua jenis saus PD X melihat dari data permintaan pesanan konsumen.Setelah konsumen melakukan pemesanan produk yang diinginkan berserta banyaknya jumlah produk tersebut ke departemen pemasaran, maka pesanan konsumen akan diproses ke bagian PPIC untuk direncanakan kapan pesanan tersebut akan diproduksi. Namun dalam melakukan kegiatan produksi tersebut produksi mengalami keterlambatan dalam memenuhi permintaan konsumen.Berikut adalah tabel permintaan produksi saus pada periode bulan Juli - Agustus

\begin{tabular}{|c|c|c|c|c|c|}
\hline Kemasan & Produk & $\begin{array}{c}\text { Batas } \\
\text { Waktu }\end{array}$ & $\begin{array}{l}\text { Waktu } \\
\text { Selesai }\end{array}$ & $\begin{array}{c}\text { Permintaan } \\
\text { (Dus/Krat) }\end{array}$ & Keterangan \\
\hline \multirow{6}{*}{ DUS } & \multirow{2}{*}{ SSD } & $07 / 07 / 18$ & $07 / 07 / 18$ & 111470 & Terlambat \\
\hline & & $09 / 08 / 18$ & $11 / 0 \$ / 18$ & $99 \$ 35$ & Terlambat \\
\hline & \multirow{2}{*}{ S58D } & $18 / 07 / 18$ & $18 / 07 / 18$ & 11450 & Tepat \\
\hline & & $20 / 08 / 18$ & $18 / 08 / 18$ & 12450 & Tepat \\
\hline & \multirow{2}{*}{ SBD } & $26 / 07 / 18$ & $2(2 / 07 / 18$ & 3898 & Tepat \\
\hline & & $27 / 08 / 18$ & $27 / 08 / 18$ & 5372 & Tepat \\
\hline \multirow{6}{*}{ KRAT } & \multirow{2}{*}{ SSK } & $13 / 07 / 18$ & $16 / 07 / 18$ & 41444 & Terlambat \\
\hline & & $15 / 08 / 18$ & $16 / 08 / 18$ & 40996 & Terlambat \\
\hline & \multirow[b]{2}{*}{$\mathrm{S} 58 \mathrm{~K}$} & $21 / 07 / 18$ & $21 / 07 / 18$ & 10350 & Tepat \\
\hline & & $24 / 08 / 18$ & $24 / 88 / 18$ & 10400 & Tepat \\
\hline & \multirow{2}{*}{ SBK } & $28 / 07 / 18$ & $26 / 07 / 18$ & 1840 & Tepat \\
\hline & & $29 / 08 / 18$ & $28 / 08 / 18$ & 1525 & Tepat \\
\hline \multicolumn{6}{|c|}{ Keterangan : } \\
\hline SSD & \multicolumn{5}{|c|}{$=$ Sambal Sedap kemasan dus } \\
\hline SSK & \multicolumn{5}{|c|}{$=$ Sambal Sedap kemasan krat } \\
\hline S58D & \multicolumn{5}{|c|}{$=$ Sambal 58 kemasan dus } \\
\hline S58K & \multicolumn{5}{|c|}{$=$ Sambal 58 kemasan krat } \\
\hline SBD & \multicolumn{5}{|c|}{$=$ Sambal Surabraja kemasan dus } \\
\hline SBK & \multicolumn{5}{|c|}{$=$ Sambal Surabraja kemasan krat } \\
\hline
\end{tabular}
2018.

Tabel 1. Permintaan Pada Produksi Saus Bulan Juli - Agustus 2018

Berdasarkan tabel permintaan diatas, sistem penjadwalan yang diterapkan pada perusahaan saus tersebut menggunakan metode FCFS dalam menyelesaikan semua pesanan pelanggannya. Namun perusahaan masih 
mengalami keterlambatan dalam proses pengerjaanya. Keterlambatan tersebut bisa disebabkan oleh beberapa faktor, diantaranya yaitu disebabkan karena jumlah tenaga kerja yang digunakan kurang, jumlah mesin dan peralatan Kerja yang digunakan terbatas sedangkan permintaan dari konsumen yang masuk cukup banyak, dan tidak teratur dalam menjadwalkan proses produksinya. Sehingga membuat proses produksi saus pada bulan Juli dan Agustus mengalami keterlambatan.

Dilihat dari tabel diatas, diketahui bahwa saus sambal sedap kemasan dus (Ssd) maupun kemasan krat (Ssk) pada bulan juli dan agustus mengalami keterlambatan dalam produksinya. Hal ini yang akan difokuskan oleh penulis untuk mengolah dan memperhitungkan permintaan saus sambal sedap pada bulan tersebut. Berikut adalah perhitungan menggunakan metode job sequencing :

\section{Metode FCFS}

\begin{tabular}{cccccc}
\multicolumn{6}{c}{ Tabel 2. Metode FCFS bulan Juli } \\
\hline No. & Order & Quantity & $\begin{array}{c}\text { Proses } \\
\text { Time } \\
\text { (hari) }\end{array}$ & $\begin{array}{c}\text { Completion } \\
\text { Time (hari) }\end{array}$ & $\begin{array}{c}\text { Due Date } \\
\text { (hari) }\end{array}$ \\
\hline 1 & SSD & 7550 & 2 & 2 & 20 \\
2 & SSK & 5530 & 2 & 4 & 20 \\
3 & SSK & 2550 & 1 & 5 & 10 \\
4 & SSD & 9220 & 2 & 7 & 20 \\
5 & SSK & 6390 & 3 & 10 & 30 \\
6 & SSD & 6410 & 1 & 11 & 10 \\
7 & SSD & 7260 & 2 & 13 & 20 \\
8 & SSD & 6850 & 1 & 14 & 10 \\
9 & SSK & 7344 & 2 & 16 & 20 \\
10 & SSK & 5460 & 2 & 18 & 20 \\
11 & SSD & 6550 & 1 & 19 & 10 \\
12 & SSD & 8875 & 2 & 21 & 20 \\
\hline
\end{tabular}

Berdasarkan tabel 2maka dapat diketahui perhitungan waktu rata-rata penyelesaian, keterlambatan rata-rata dan utilisasi dengan metode FCFS yaitu sebagai berikut :

a. Waktu penyelesaian rata-rata $=\frac{217}{15}=14,47$ Hari

b. Utilisasi $=\frac{28}{217} \times 100=13 \%$

c. Keterlambatan rata-rata $=\frac{26}{15}=1,73 \mathrm{Hari}$

Tabel 3. Metode FCFS bulan Agustus

\begin{tabular}{|c|c|c|c|c|c|c|}
\hline No. & Order & Quantity & $\begin{array}{c}\text { Proses } \\
\text { Time } \\
\text { (hari) }\end{array}$ & $\begin{array}{c}\text { Completion } \\
\text { Time } \\
\text { (hari) }\end{array}$ & $\begin{array}{l}\text { Due } \\
\text { Date } \\
\text { (hari) }\end{array}$ & $\begin{array}{c}\text { Lateness } \\
\text { (hari) }\end{array}$ \\
\hline 1 & SSD & 7325 & 3 & 3 & 30 & 0 \\
\hline 2 & SSD & 8170 & 2 & 5 & 20 & 0 \\
\hline 3 & SSK & 6495 & 1 & 6 & 10 & 0 \\
\hline 4 & SSK & 6500 & 3 & 9 & 30 & 0 \\
\hline 5 & SSD & 6540 & 1 & 10 & 10 & 0 \\
\hline 6 & SSD & 25850 & 4 & 14 & 30 & 0 \\
\hline 7 & SSK & 6980 & 2 & 16 & 20 & 0 \\
\hline 8 & SSD & 6490 & 1 & 17 & 10 & 7 \\
\hline 9 & SSK & 8410 & 2 & 19 & 20 & 0 \\
\hline 10 & SSD & 17510 & 3 & 22 & 30 & 0 \\
\hline 11 & SSD & 6680 & 1 & 23 & 10 & 13 \\
\hline 12 & SSK & 7235 & 2 & 25 & 20 & 5 \\
\hline 13 & SSD & 16890 & 2 & 27 & 20 & 7 \\
\hline 14 & SSD & 7870 & 2 & 29 & 20 & 9 \\
\hline \multicolumn{3}{|c|}{ Total } & 29 & 225 & 280 & 41 \\
\hline \multicolumn{3}{|c|}{ Rata-rata } & & 16.07 & & 2.93 \\
\hline \multicolumn{6}{|c|}{ Max Lateness } & 13 \\
\hline \multicolumn{6}{|c|}{ Utilitas } & $13 \%$ \\
\hline
\end{tabular}

Berdasarkan tabel 3 maka dapat diketahui perhitungan waktu rata-rata penyelesaian, keterlambatan rata-rata dan utilisasi dengan metode FCFS yaitu sebagai berikut :

a. Waktu penyelesaian rata-rata $=\frac{225}{14}=16,07$ Hari

b. Utilisasi $=\frac{29}{225} \times 100=13 \%$

c. Keterlambatan rata-rata $=\frac{41}{14}=2,93$ Hari

Tabel 4. Hasil perhitungan dari FCFS bulan Juli

\begin{tabular}{clc}
\hline No & \multicolumn{1}{c}{ Deskripsi } & Hasil \\
\hline 1 & Waktu Penyelesaian (Hari) & 217 \\
2 & Waktu Penyelesaian Rata-Rata & 14,47 \\
3 & (Hari) & 26 \\
4 & Keterlambatan (Hari) & 1,73 \\
5 & Keterlambatan Rata-Rata (Hari) & 9 \\
6 & Utilisasi (\%) & $13 \%$ \\
& & SSD, SSK, SSK, SSD, SSK, \\
7 & Urutan Pekerjaan & SSD, SSD, SSD, SSK, SSK, \\
& & SSD, SSD, SSD, SSD, SSK \\
\hline
\end{tabular}

Tabel 5. Hasil perhitungan dari FCFS bulan Agustus

\begin{tabular}{clc}
\hline No & \multicolumn{1}{c}{ Deskripsi } & Hasil \\
\hline 1. & Waktu Penyelesaian (Hari) & 225 \\
2. & Waktu Penyelesaian Rata-Rata & 16,07 \\
3. & Keterlambatan (Hari) & 41 \\
4. & Keterlambatan Rata-Rata (Hari) & 2,93 \\
5. & Keterlambatan Tertinggi(Hari) & 13 \\
6. & Utilisasi (\%) & $13 \%$ \\
& & SSD, SSD, SSK, SSK, SSD, \\
7. & Urutan Pekerjaan & SSD, SSK, SSD, SSK, SSD, \\
& & SSD, SSK, SSD, SSD. \\
\hline
\end{tabular}

2. Metode LPT

Untuk tabel dan perhitungan metode LPT itu hampir sama dengan tabel dan perhitungan metode FCFS hanya saja yang membedakan itu dilihat dari waktu prosesnya. Untuk metode LPT pekerjaan yang memiliki waktu penyelesaian lebih panjang akan diproses terlebih dahulu. Berikut adalah hasil perhitungan menggunakan metode LPT :

Tabel 6. Hasil perhitungan dari LPT bulan Juli

\begin{tabular}{clc}
\hline No & \multicolumn{1}{c}{ Deskripsi } & Hasil \\
\hline 1. & Waktu Penyelesaian (Hari) & 259 \\
2. & Waktu Penyelesaian Rata-Rata & 17,27 \\
3. & (Hari) & 78 \\
4. & Keterlambatan (Hari) & 5,2 \\
5. & Keterlambatan Rata-Rata (Hari) & 8 \\
6. & Utilisasi (\%) & $11 \%$ \\
& & SSK, SSD, SSD, SSK, SSD, \\
7. & Urutan Pekerjaan & SSD, SSK, SSK, SSD, SSD, \\
& & SSK, SSK, SSD, SSD, SSD. \\
\hline
\end{tabular}

Tabel 7. Hasil perhitungan dari LPT bulan Agustus

\begin{tabular}{clc}
\hline No & \multicolumn{1}{c}{ Deskripsi } & Hasil \\
\hline 1. & Waktu Penyelesaian (Hari) & 264 \\
2. & Waktu Penyelesaian Rata-Rata & 18,86 \\
3. & (Hari) & Keterlambatan (Hari) \\
4. & Keterlambatan Rata-Rata (Hari) & 79 \\
5. & Keterlambatan Tertinggi(Hari) & 5,64 \\
6. & Utilisasi (\%) & 19 \\
& & $11 \%$ \\
7. & Urutan Pekerjaan & SSD, SSD, SSK, SSD, SSD, \\
& & SSK, SSK, SSK, SSD, SSD, \\
\end{tabular}


3. Metode SPT

Untuk tabel dan perhitungan metode SPT itu hampir sama dengan tabel dan perhitungan metode FCFS hanya saja yang membedakan itu dilihat dari waktu prosesnya. Untuk metode SPT pekerjaan yang memiliki waktu penyelesaian lebih pendek akan diproses terlebih dahulu. Berikut adalah hasil perhitungan menggunakan metode SPT :

\begin{tabular}{clc}
\multicolumn{2}{c}{ Tabel 8. Hasil perhitungan dari SPT bulan Juli } \\
\hline No & \multicolumn{1}{c}{ Deskripsi } & Hasil \\
\hline 1. & Waktu Penyelesaian (Hari) & 189 \\
2. & Waktu Penyelesaian Rata-Rata & 12,6 \\
3. & Keterlambatan (Hari) & 2 \\
4. & Keterlambatan Rata-Rata (Hari) & 0,8 \\
5. & Keterlambatan Tertinggi(Hari) & 8 \\
6. & Utilisasi (\%) & $15 \%$ \\
& & SSK, SSD, SSD, SSD, SSD, \\
7. & Urutan Pekerjaan & SSK, SSD, SSD, SSK, SSK, \\
& & SSD, SSD, SSK, SSK, SSD. \\
\hline
\end{tabular}

\begin{tabular}{clc}
\multicolumn{3}{c}{ Tabel 9. Hasil perhitungan dari SPT bulan Agustus } \\
\hline No & \multicolumn{1}{c}{ Deskripsi } & Hasil \\
\hline 1. & Waktu Penyelesaian (Hari) & 172 \\
2. & Waktu Penyelesaian Rata-Rata & 12,29 \\
3. & Keterlambatan (Hari) & 0 \\
4. & Keterlambatan Rata-Rata (Hari) & 0 \\
5. & Keterlambatan Tertinggi(Hari) & 0 \\
6. & Utilisasi (\%) & $17 \%$ \\
& Urutan Pekerjaan & SSK, SSD, SSD, SSD, SSD, \\
7. & SSK, SSK, SSK, SSD, SSD, \\
& & SSD, SSK, SSD, SSD. \\
\hline
\end{tabular}

\section{Metode EDD}

Untuk tabel dan perhitungan metode EDD itu hampir sama dengan tabel dan perhitungan metode FCFS hanya saja yang membedakan itu dilihat dari waktu prosesnya. Untuk metode EDD pekerjaan dengan batas waktu paling awal akan diproses terlebih dahulu. Berikut adalah hasil perhitungan menggunakan metode EDD :

Tabel 10. Hasil perhitungan dari EDD bulan Juli

\begin{tabular}{|c|c|c|}
\hline No & Deskripsi & Hasil \\
\hline 1. & Waktu Penyelesaian (Hari) & 189 \\
\hline 2. & $\begin{array}{l}\text { Waktu Penyelesaian Rata- } \\
\text { Rata (Hari) }\end{array}$ & 12,6 \\
\hline 3. & Keterlambatan (Hari) & 2 \\
\hline & $\begin{array}{l}\text { Keterlambatan Rata-Rata } \\
\text { i) }\end{array}$ & 0,8 \\
\hline 5. & $\begin{array}{l}\text { Keterlambatan } \\
\text { Tertinggi(Hari) }\end{array}$ & 8 \\
\hline 6. & Utilisasi $(\%)$ & $15 \%$ \\
\hline 7. & Urutan Pekerjaan & $\begin{array}{l}\text { SSK, SSD, SSD, SSD, SSD, } \\
\text { SSK, SSD, SSD, SSK, SSK, } \\
\text { SSD, SSD, SSK, SSK, SSD. }\end{array}$ \\
\hline
\end{tabular}

Tabel 11. Hasil perhitungan dari EDD bulan Agustus

\begin{tabular}{clc}
\hline No & \multicolumn{1}{c}{ Deskripsi } & Hasil \\
\hline 1. & Waktu Penyelesaian (Hari) & 172 \\
2. & Waktu Penyelesaian Rata-Rata & 12,29 \\
3. & Keterlambatan (Hari) & 0 \\
4. & Keterlambatan Rata-Rata (Hari) & 0 \\
5. & Keterlambatan Tertinggi(Hari) & 0 \\
6. & Utilisasi (\%) & $17 \%$ \\
& & SSK, SSD, SSD, SSD, SSD, \\
7. & Urutan Pekerjaan & SSK, SSK, SSK, SSD, SSD, \\
& & SSD, SSK, SSD, SSD. \\
\hline
\end{tabular}

Setelah dilakukan perhitungan dari masing-masing metode FCFS, SPT, LPT, dan EDD. Maka langkah selanjutnya adalah melihatdan membandingkan hasil pengukuran efektifitas dari keempat metode tersebut. Hasil yng dibandingkan dari perhitungan tersebut antara laintotal waktu penyelesaian pesanan, total waktu keterlambatan, dan nilai dari utilitas nya. Berikut ini adalah hasil perbandingan dari keempat metode tersebut :

\begin{tabular}{|c|c|c|c|c|c|c|}
\hline Metode & $\begin{array}{c}\text { Waktu } \\
\text { Penyelesaian } \\
\text { (hari) }\end{array}$ & $\begin{array}{c}\text { Waktu } \\
\text { penyelesaian } \\
\text { rata-rata (hari) }\end{array}$ & $\begin{array}{l}\text { Keterlambatan } \\
\text { (hari) }\end{array}$ & $\begin{array}{l}\text { Keterlambatan } \\
\text { rata-rata (hari) }\end{array}$ & $\begin{array}{l}\text { Keterlambatan } \\
\text { Tertinggi (hari) }\end{array}$ & $\begin{array}{c}\text { Utilisasi } \\
(\%)\end{array}$ \\
\hline FCFS & 217 & 14,47 & 26 & 1,73 & 9 & $13 \%$ \\
\hline LPT & 259 & 17,27 & 78 & 5,2 & 8 & $11 \%$ \\
\hline SPT & 189 & 12,6 & 2 & 0,8 & 8 & $15 \%$ \\
\hline EDD & 189 & 12,6 & 2 & 0,8 & 8 & $15 \%$ \\
\hline \multicolumn{7}{|c|}{ Tabel 13.Hasil perbandingan dari job sequencing Bulan Agustus } \\
\hline Metode & $\begin{array}{c}\text { Waktu } \\
\text { Penyelesaian } \\
\text { (hari) }\end{array}$ & $\begin{array}{c}\text { Waktu } \\
\text { penyelesaian } \\
\text { rata-rata (hari) }\end{array}$ & $\begin{array}{c}\text { Keterlambatan } \\
\text { (hari) }\end{array}$ & $\begin{array}{l}\text { Keterlambatan } \\
\text { rata-rata (hari) }\end{array}$ & $\begin{array}{l}\text { Keterlambatan } \\
\text { Tertinggi (hari) } \\
\end{array}$ & $\begin{array}{c}\text { Utilisasi } \\
(\%)\end{array}$ \\
\hline FCFS & 225 & 16,07 & 41 & 2,93 & 13 & $13 \%$ \\
\hline LPT & 264 & 18,86 & 79 & 5,64 & 19 & $11 \%$ \\
\hline SPT & 172 & 12,29 & 0 & 0 & 0 & $17 \%$ \\
\hline EDD & 172 & 12,29 & 0 & 0 & 0 & $17 \%$ \\
\hline
\end{tabular}

Dilihat dari tabel diatas perbandingan terlihat dari waktu penyelesaiannya.Waktu penyelesaian untuk metode perusahaan yaitu FCFS pada bulan Juli selama 217 hari dan 225 hari untuk bulan Agustus. Sedangkan untuk metode SPT dan EDD selama 189 hari pada bulan Juli dan 172 hari pada bulan Agustus. Namun selain memperhitungkan dan membandingkan data secara manual, penulis juga memperhitungkan data dengan bantuan software POM for windows 5.0 untuk melihat apakah hasil yang dihitung sebelumnya itu sudah benar dan sama dengan perhitungan software. Berikut adalah tampilan dan hasil dari perhitungan menggunakan software POM for windows5.0 :

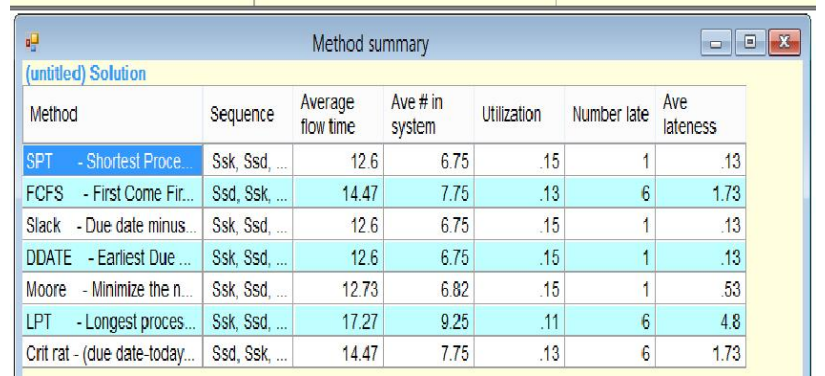

Gambar 2.Hasil Perhitungan permintaan bulan Juli

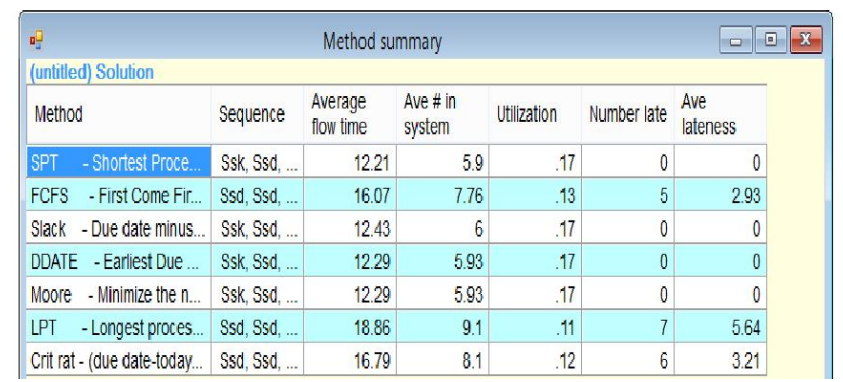

Gambar 3.Hasil Perhitungan permintaan bulan Agustus

Setelah dilihat dan dibandingkan hasil dari perhitungan pada tabel dan gambar diatas untuk bulan Juli dan Agustus ternyata metode EDD dan SPT merupakan metode yang paling optimal dari metode pembanding lainnya, hasil yang dilihat dari metode EDD dan SPT ini adalah waktu proses penyelesaian produk yang paling cepat dari metode lainya 
yaitu selama 189 hari, mempunyai waktu keterlambatan paling sedikit yaitu 2 hari, dan nilai utilitasi sebesar $15 \%$ pada bulan Juli. Pada bulan Agustus diperoleh selama 172 hari, mempunyai waktu keterlambatan paling sedikit yaitu 0 hari, dan nilai utilitasi sebesar 17\%. Dengan urutan job pada bulan Juli yaitu Ssk, Ssd, Ssd, Ssd, Ssd, Ssk, Ssd, Ssd, Ssk, Ssk, Ssd, Ssd, Ssk, Ssk, Ssd sebanyak 15 pesanan. Dan urutan job pada bulan Agustus yaitu Ssk, Ssd, Ssd, Ssd, Ssd, Ssk, Ssk, Ssk, Ssd, Ssd, Ssd, Ssk, Ssd, Ssd sebanyak 14 pesanan.

\section{SIMPULAN}

PD X menerapkan metode FCFS pada proses produksinya. Penerapan ini memang dinilai adil karena memprioritaskan pesanan yang datang terlebih dahulu, namun metode ini kurang efektif bagi perusahaan.Dari hasil perbandingan metode FCFS, SPT, LPT dan EDD. Metode penjadwalan produksi yang optimal dalam penelitian ini yaitu metode EDD (Earlist Due Date) dan SPT (shortest processing time) karena dari semua metode, metode EDD dan SPT lah yang paling optimal dilihat dari hasil perhitungan dalam pengolahan datanya. Dengan adanya metode ini diharapkan perusahaan mampu memproduksi pesanan secara tepat waktu dengan megoptimalkan lagi jumlah tenaga kerja dan jumlah mesin atau peralatan yang digunakan sehingga proses produksi pun berjalan secara optimal.

\section{UCAPAN TERIMA KASIH}

Ucapan terima kasih terutama ditujukan kepada kedua orang tua atas doa dan dukungan yang diberikan. Terimakasih ditunjukan juga kepada semua dosen pembimbing, teman dan sahabat yang selalu memberi bimbingan dan dorongan untuk menyelesaikan penelitian ini.

\section{REFERENS}

[1] Nasution, dkk. Perencanaan dan Pengendalian Produksi. Yogyakarta: Penerbit Graha Ilmu. 2008.

[2] R. Ginting, Sistem Produksi. Yogyakarta: Penerbit Graha Ilmu. 2012.

[3] B. A. Irvantoro, Penerapan Metode Asas Prioritas Pada Proses Produksi Studi Pada Koperasi Batur Jaya, Kabupaten Klaten, Provinsi Jawa Tengah. Jurnal: jurnal ilmiyah teknik industri, 11 (2), 1-12. 2012.

[4] Kusnadi, dkk. Sistem Operasi. Yogyakarta: Penerbit Andi. 2008.

[5] V. Gasper, Production Planning And Inventory Control. Berdasarkan Pendekatan Sistem Terintegrasi MRP II \& JIT menuju Manufacturing 21. Jakarta: PT Gramedia Pustaka Utama. 2005.

[6] R. B .Yosan, dan H. Erwandi, Penjadwalan Produksi dengan Menggunakan Metode Fcfs, Edd, Spt dan Lpt Untuk Meningkatkan Produktivitas Kerja. Jurnal: jurnal ilmiyah pasti, 6 (1), 97 - 107.

[7] H. Jay, dan B. Render. Manajemen Operasi Edisi 7 Jilid 2. Salemba Empat: Jakarta. 2005

[8] M. I. Hasan, Dkk. Perencanaan Pencampuran Batubara Software Pom-Qm Untuk Optimalisasi Stockpile Di Port Site Pt. Jembayan Muarabara
Tenggarong, Provinsi Kalimantan Timur.Jurnal : Teknologi Mineral FT UNMUL. 6 (1), 32 - 37. 2018.

[9] Z. Hertawan. Pratikum Manajemen Operasional Dengan Software POM QM for Windows. F. E Ekonomi Universitas Muhammadiyag: Bengkulu. 2011.

[10] B. Wahyon. Mesin dan Peralatan. Universitas Sebelas Maret. Pendidikan Ekonomi: Surakarta. 2011. 